\title{
Características Demográficas do Centro Histórico de São Luís
}

\author{
João Ricardo Costa Silva* \\ José Odval Alcântara Júnior* *
}

\section{RESUMO}

O artigo tem por objetivo fazer uma análise sobre as alterações demográficas no centro histórico de São Luís no decorrer de três décadas, através da aglutinação de dados estatísticos, nas quais projetos e ações urbanísticas de preservação do conjunto arquitetônico, transformaram o referido local no principal símbolo representativo da cidade. Na reflexão, são trazidos dados de natureza empírica oriundos de uma classificação dos moradores residentes e domicílios do referido espaço urbano, tendo por escopo contribuir para o melhor refinamento das reflexões sobre as políticas públicas para preservação do centro histórico de São Luís.

Palavras-chaves: Patrimônio histórico; Preservação; Demografia.

* Mestre e Doutor em Ciências Sociais pela Universidade Federal do Maranhão.

** Sociólogo, docente no Curso de Graduação em Ciências Sociais e do Programa de Pósgraduação em Ciências Sociais/UFMA. Doutorado em Ciências Sociais/PUC-SP. Este artigo baseou-se na Tese intitulada: "Patrimônio Arquitetônico: os desafios para a preservação do Centro Histórico de São Luís”, de autoria do primeiro autor e orientação do segundo autor, defendida em 2016, no Programa de Pós-graduação em Ciências Sociais da Universidade Federal do Maranhão. 


\begin{abstract}
DEMOGRAPHIC CHARACTERISTICS OF THE HISTORIC CENTER OF SÃO LUÍS

The objective of this article is to analyze the demographic changes in the historical center of São Luís over three decades, through the agglutination of statistical data, in which projects and urbanistic actions to protect the architectural complex, transformed the said place into the main representative of the city. The research is traced by empirical data, that is, one of the resident and domiciled domains of urban space, aiming to contribute to a better refinement of the reflections on public policies for the preservation of the historical center of São Luís.
\end{abstract}

Keywords: Heritage; Preservation; Demography.

\title{
Introdução
}

Um obstáculo às pesquisas sobre a área de preservação histórica de São Luís se perfaz na pouca disponibilidade de dados empíricos sociodemográficos que possam servir como meio de análise para cotejar variações ao longo do tempo em relação aos projetos de políticas públicas executadas desde o início da década de 1980. A recomendação de Nairóbi, já apontava sobre a importância de estudos na esfera do patrimônio arquitetônico para além da estrutura edificada.

Além dessa investigação arquitetónica, são necessários estudos pormenorizados dos dados e das estruturas sociais, económicas, culturais e técnicas, assim como do contexto urbano ou regional mais amplo. Esses estudos deveriam abranger, se possível, dados demográficos e uma análise das actividades económicas, sociais e culturais, os modos de vida e as relações sociais, os problemas fundiários, infraestrutura urbana, o estado do sistema viário, as redes de comunicação e as inter-relações recíprocas da zona protegida com as zonas circundadas. As autoridades competentes deveriam atribuir suma importância a esses estudos e compreender que, sem eles, não seria possível estabelecer planos eficazes de salvaguarda (UNESCO, 2009, p. 197).

Aludida recomendação realça o aspecto demográfico, dentre outros, como de caráter essencial para o embasamento de políticas públicas de preservação de conjuntos históricos.

O conjunto arquitetônico possui uma área extensa com 250 hectares, qualquer tentativa de trabalhar com dados quantitativos torna-se um desafio 
o levantamento dos mesmos. Visando contornar essa dificuldade de obter dados quantitativos para auxiliar na construção de um quadro de possíveis variações das características da população residente na área de tombamento federal foi realizado um levantamento de dados oriundos do Instituto Brasileiro de Geografia e Estatística - IBGE, com o intuito de levantar e analisar criticamente categorias estatísticas sobre o referido espaço no sentido de “desembocar em informações específicas e novas que apresentem um interesse peculiar” (MERLLIÉ, 1996, p. 109).

Foram classificados dados dos três últimos Censos Demográficos, por ser “a mais complexa operação estatística realizada por um país, quando são investigadas as características de toda a população e dos domicílios do Território Nacional” (IBGE, 2011). A utilização dos censos demográficos foi tomada por pesquisarem todos os domicílios do País, desta forma, constituem uma grande fonte de referência para o conhecimento das características das condições de vida da população em todos os municípios e em seus recortes territoriais internos.

Contudo, inicialmente, esbarrou-se no problema da falta de norma legal que delimitasse os bairros de São Luís por ausência de legislação para regulamentação da temática. Para superar esse obstáculo a pesquisa trabalhou com o denominado setor censitário ${ }^{1}$, que é a menor unidade geográfica utilizada pelo IBGE, sendo formado em áreas urbanas por um ou mais conjuntos de quadras de acordo com o quantitativo de domicílios existentes.

Assim, foram tabulados em planilhas dados selecionados dos Censos Demográficos de 1991, 2000 e 2010², com utilização dos agregados por setor censitário. Um dado agregado é obtido através do somatório dos valores de quesitos contidos em um questionário respondido pelos informantes da pesquisa, podendo serem associados a unidades territoriais ou recortes cronológicos que o qualificam.

1 O setor censitário é a menor unidade territorial, com limites físicos identificáveis em campo, com dimensão adequada à operação de pesquisas e cujo conjunto esgota a totalidade do Território Nacional, o que permite assegurar a plena cobertura do País (IBGE, 2003, p. 3).

2 A ideia inicial era fazer uma séria estatística desde de 1980, contudo não se foi possível localizar um mapa de setores censitários de 1980 para o município de São Luís, e assim, sem uma plena confirmação da manutenção dos setores, se preferiu não inserir dados daquela época. 
Figura n 1 - Mapa de localização dos setores censitários.

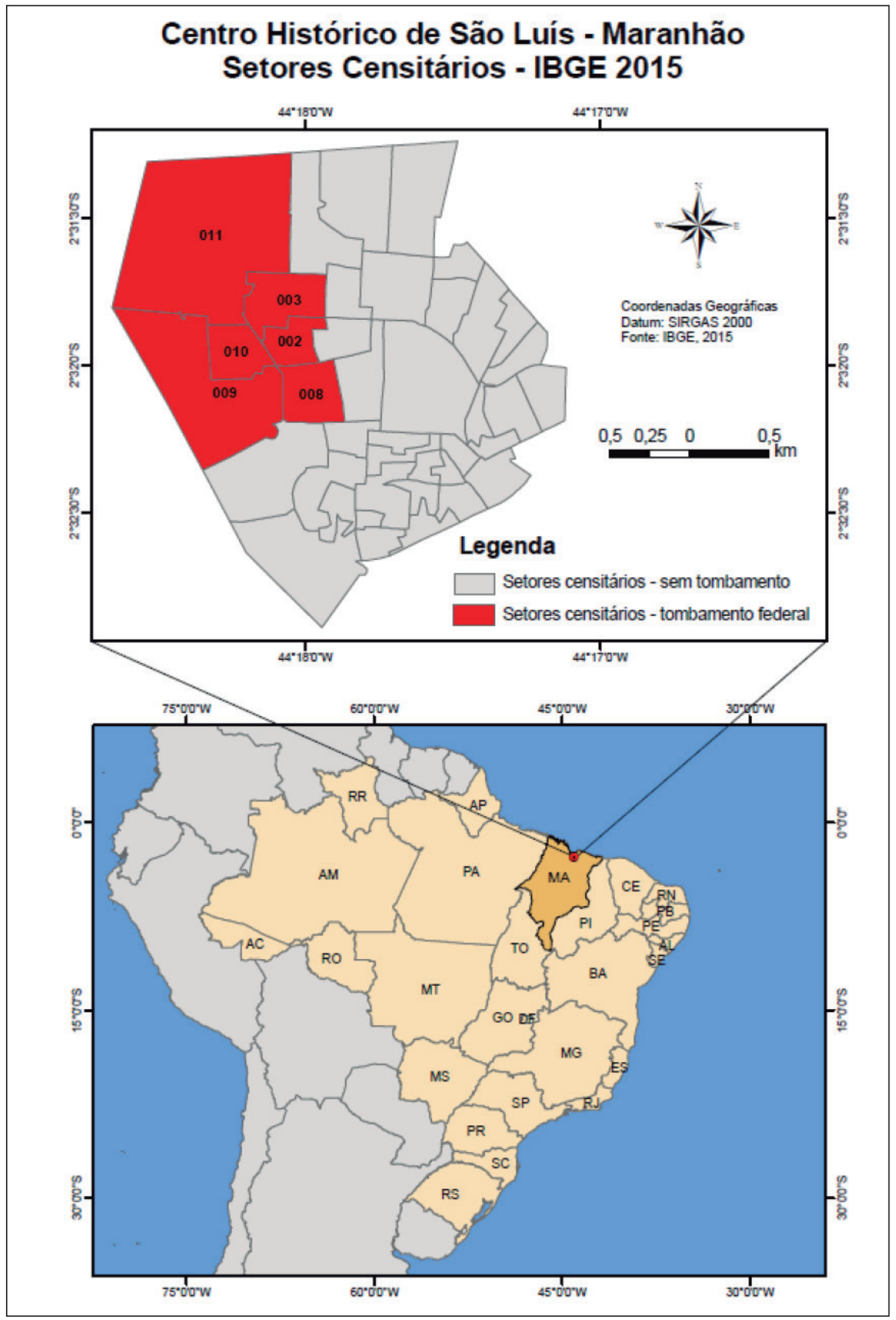

Fonte: IBGE 
Os agregados do censo foram concebidos como cadastros básicos de áreas para a seleção de amostras para as pesquisas domiciliares. De acordo com a publicação Agregados por Setores Censitários dos Resultados do Universo do Censo, $2^{\text {a }}$ edição de 2000, “as variáveis de descrição da divisão territorial brasileira e algumas variáveis de porte ou tamanho dos setores, para estratificação dos setores e seleção de amostras com probabilidades desiguais" (IBGE, 2003, p. 3).

Figura 2 - Limites do Centro Histórico.



Fonte: LOPES, 2008, p. 46

A utilização dos agregados de setores censitários se apresentou como um caminho viável, pois a partir do Censo Demográfico de 1991, estes arquivos “passaram a incorporar mais variáveis em nível de setor, como forma de 
produzir rapidamente resultados para subdivisões geográficas ${ }^{3}$ não atendidas pelas publicações do censo" (IBGE, 2003, p. 3). Desse modo, em razão da ausência de delimitação legal dos Bairros em São Luís, ocorre uma não divulgação de dados neste nível geográfico. O fato do município não dispor da referida delimitação oficial interna é fator negativo para uma melhor organização de seu espaço territorial, bem como para o planejamento e monitoramento de políticas públicas.

Como forma de conseguir trabalhar com os dados quantitativos oriundos da área do perímetro federal de tombamento fez-se a confrontação entre os setores censitários e a área histórica, como metodologia adotada para superar a inexistência da delimitação legal de Bairros. Deste cruzamento foram selecionados os seguintes setores: 211130005000002, 211130005000003, 211130005000008, 211130005000009, 211130005000010 e 211130005000011. Esses seis setores reunidos não possuem perímetro exato ao da área federal (figura $\mathrm{n}^{\circ} 2$ ), mas se apresentam de forma bastante aproximada, conforme da comparação com a figura $\mathrm{n}^{0} 1$.

Após seleção dos seis setores censitários realizou-se a delimitação de quais temas, dentre os inúmeros existentes, seriam escolhidos para tratamento e construção de tabulações que informassem a situação da área. Os temas selecionados foram: características gerais dos moradores e dos domicílios. Com os dados brutos foram estabelecidas as variáveis para serem analisadas, e com isso, passou-se para a etapa de tabulação.

Os autores do presente artigo, consideraram essa aglomeração de setores censitários através da reunião de setores censitários agregados, de modo a se formar uma unidade de análise espacial (área de tombamento federal). Com essa unidade, foram elaboradas tabulações para constituição de indicadores demográficos dos moradores e domicílios do centro histórico de São Luís. As informações decorrentes do estudo são pertinentes, pois permitem a utilização de informações precisas na elaboração das políticas públicas para essa área singular da cidade.

Com base no tratamento dos dados brutos quantitativos e sua transformação em conhecimento, foram construídos gráficos, que serviram como material para melhor mensuração visual das reflexões qualitativas desenvol-

3 Alguns dos níveis territoriais do Censo Demográfico: Brasil, Grandes Regiões, Unidades da Federação, Municípios, Bairros e Distritos. 
vidas, pois a proteção de centros históricos implica em um universo de campos inter-relacionados para um tratamento integral do patrimônio histórico incluindo o componente demográfico.

\section{A dinâmica demográfica do Centro Histórico}

A reflexão dos projetos e ações patrimoniais e seu impacto sociodemográfico no tecido social do centro histórico é um elemento capaz de possibilitar novos debates sobre como em mais de três décadas de ações dos órgãos responsáveis na gestão do patrimônio orientaram e deliberaram prioridades desde suas primeiras intervenções.

As primeiras obras do Programa de Preservação e Revitalização do centro histórico de São Luís - PPRCH, iniciadas através do Subprograma de Obras da Praça do Comércio em pontos da Praia Grande nos anos de 1981 e 1982, “com a realização das obras da Feira da Praia Grande, Albergue, Beco da Prensa, Praça da Praia Grande e obras de urbanização em geral, representando investimentos da ordem de 2,5 milhões" (ANDRÈS, 1998, p.85). Todas as referidas obras se encontravam no perímetro de tombamento federal.

Ao montar uma classificação dos moradores do centro histórico se torna possível traçar uma melhor configuração do perfil das pessoas residentes na área tombada, inclusive com dados fidedignos da variação do número de residentes ao longo das décadas, pois inúmeros trabalhos aduzem sobre o esvaziamento populacional na área nas últimas décadas, mas sem apontarem dados empíricos do fenômeno.

Em mais de três séculos, a ocupação urbana ficou restrita basicamente ao núcleo fundacional até meados século XIX, confinada em pequena área geográfica delimitada pelos rios Anil e Bacanga, tendo começado sua expansão além dos limites do núcleo urbano antigo em direção ao interior da ilha através do denominado "Caminho Grande" (LOPES, 2008, p. 14).

A pesquisa aponta que, passados dez anos das primeiras intervenções do PPRCH no início da década de 1980, na tentativa de reverter a situação de abandono e degradação do conjunto arquitetônico tombado, o referido espaço se apresentava com uma população residente que somava 5.447 (cinco mil, quatrocentos e quarenta e sete) pessoas de acordo com a tabulação construída com dados oriundos do censo demográfico de 1991, sendo destaque a predominância feminina. Do total de pessoas residentes no centro histórico 
de São Luís, 3.187 (três mil, cento e oitenta e sete) era do sexo feminino e 2.260 (dois mil, duzentos e sessenta) do sexo masculino.

Essa característica demográfica, no perfil dos residentes por sexo, com um número de indivíduos do gênero feminino bem acima do masculino também é observada na última jornada censitária do século XX, que também foi a primeira após a inserção do centro histórico na Lista do Patrimônio Mundial da Humanidade ocorrida no ano 2000. Isso mostra uma pequena variação negativa no número total de residentes no centro histórico. Em 2000 esse número decaiu para 4.645 (quatro mil, seiscentos e quarenta e cinco) residentes. Assim, no espaço de nove anos ocorreu uma variação negativa de 14,73\% no total de residentes. É necessário enfatizar que a inserção na Lista do Patrimônio Mundial em 1997 não conseguiu ter efeito na atração/ manutenção de residentes na área.

No que se refere à divisão por gênero foi mantida a predominância feminina sobre a masculina. Destarte, no último censo do século XX, 2.708 (duas mil, setecentos e oito) eram do sexo feminino e 1.937 (mil, novecentos e trinta e sete) do sexo masculino. A diferença populacional entre os sexos na área tombada é superior da apresentada na cidade de São Luís ${ }^{4}$.

O primeiro censo demográfico do século XXI, ocorrido em $2010^{5}$, evidencia uma aceleração do esvaziamento populacional de residentes no centro histórico, sendo recenseadas 2.993 (duas mil, novecentos e noventa e três) pessoas residindo na área. Esse número demonstra uma significativa diminuição de 35,57\% em comparação ao apurado dez anos antes.

Essa informação é de suma relevância, pois apesar de todo o investimento das políticas de preservação do centro histórico e da existência desde primórdios do PPRCH de uma diretriz de habitação, os dados apontam para uma constante redução do número de moradores, fato este intensificado no decorrer do primeiro decênio do século XXI.

No tocante ao quantitativo da população residente por gênero, manteve-se inalterado a relação percentual existente em 2000. Desse modo, pode-se afirmar que a redução dos residentes ocorreu de forma simétrica entre decla-

4 O Censo Demográfico 2000 registrou na cidade de São Luís percentual de 46,71\% residentes do sexo masculino e $53,29 \%$ do sexo feminino. Em 2010 , foram recenseadas $46,81 \%$ pessoas do sexo masculino e $53,19 \%$ do sexo feminino.

5 A população do município de São Luís foi recenseada com uma população de 460.320 pessoas em 1980, 695.199 em 1991, 868.047 em 2000 e 1.014.837 em 2010. 
rados do sexo masculino e feminino. Assim, foram contabilizados no censo demográfico de 2010 um total de 1.726 (mil, setecentos e vinte e seis) pessoas do sexo feminino e 1.267 (mil, duzentos e sessenta e sete) do sexo masculino, representando em termos percentuais de 58\% e $42 \%$ respectivamente.

Apesar da ampla exposição, devido à inserção na Lista do Patrimônio Mundial e dos efusivos discursos de autoridades e gestores públicos, as informações populacionais demonstram o desafio dos órgãos de gestão do patrimônio para efetivação da diretriz de "propiciar a permanência da população residente no Centro Histórico” (MARANHÃO, 1986, p. 18), pois os dados tabulados apontam uma tendência de esvaziamento populacional ao longo das últimas décadas.

O gráfico $\mathrm{n}^{\mathrm{O}} 01$ denota como apesar de toda a ênfase na importância e relevância do conjunto arquitetônico, nas falas dos agentes responsáveis por sua preservação, que os projetos para salvaguarda do patrimônio não conseguiram fazer com que essa área da cidade voltasse a ter uma nova dinâmica social e econômica. Ao contrário, verifica-se que ao longo das três últimas décadas ocorreu um progressivo esvaziamento do centro histórico com a saída de forma contínua de moradores.

Gráfico nº 01 - Variação do número de residentes.

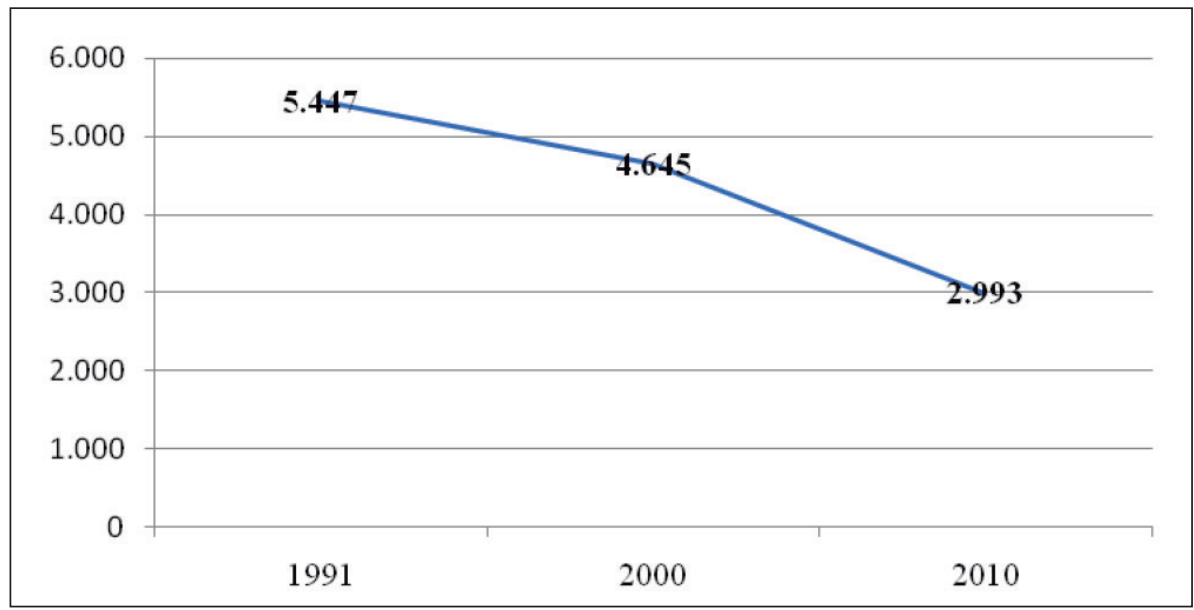

Fonte: Autoria Própria com base em dados do IBGE

No gráfico se visualiza a redução de quase metade do número absoluto de moradores com uma redução de 45\% em duas décadas. Fatores podem ser apresentados para compreensão desse fenômeno, sendo ressaltado, con- 
forme Georgia Patrícia da Silva (2010, p. 83): “O princípio da revitalização do bairro da Praia Grande recaiu na criação de mais um ponto turístico na cidade". Assim, em torno dessa premissa, foi estruturado todo o discurso de preservação do centro histórico de São Luís através dos investimentos físicos e simbólicos de proteção do patrimônio.

Em que pese, desde o nascedouro dos projetos de preservação do conjunto arquitetônico de tipologia lusa de São Luís apresentarem uma gama de diretrizes abrangentes, no intuito de buscar um amplo plano de recuperação física e funcional para o sítio histórico, o confronto entre os inúmeros projetos e planos com as informações sociodemográficas produzidas através dos dados estatísticos apontam para fragilidade das ações desenvolvidas para integração da área histórica na vida atual da urbe.

Um dos entraves para o alcance das diretrizes de revitalização no centro histórico de São Luís se assenta na falta de continuidade dos projetos ao longo do tempo, conforme asseverado por Georgia Patrícia da Silva (2010, p. 83) ao afirmar que "As descontinuidades entre as propostas voltadas para o plano e as práticas efetivas de uso do espaço emergiram, no entanto, no decorrer do tempo”. Várias ações se sucederam nas últimas décadas, mas sem fluírem dentro de um amplo e perene projeto de preservação da área tombada.

O processo de esvaziamento do centro histórico não pode ser imputado somente à ausência de uma política pública consolidada de preservação do acervo urbano, mas também se evidencia com o surgimento de uma nova configuração de ocupação do solo urbano da cidade, através da construção de novas vias e principalmente das pontes sobre o rio Anil e Bacanga.

A orla marítima passa a ser ocupada por uma classe com poder econômico mais elevado, enquanto a parte sul e sudoeste se configuram por assentamentos de origem informal iniciados por trabalhadores de baixo poder aquisitivo e que não possuem acesso a uma moradia de qualidade, e que também não é ofertada pelo Estado. Surgem conjuntos habitacionais, com uma política de habitação ao trabalhador, implantados em locais muito distantes do centro da cidade, representando um tempo muito maior de deslocamento do que aquelas ocupações próximas ao centro (PEREIRA; ALCÂNTARA JÚNIOR, 2017, p. 991).

Apesar dessa expansão para outras áreas da cidade também ser um fator de esvaziamento do centro histórico, é necessário ressaltar que a área tombada também teve destaque dentro da elaboração de novas vias, sendo 
construído um anel viário em torno do centro histórico, tornando-o "um eixo de conexão intermediária entre os deslocamentos de pessoas que ocupam a porção norte da Ilha, situada na região da orla marítima, e a parte oeste-sul, que engloba a região do Distrito Industrial e do Maracanã” (PEREIRA; ALCÂNTARA JÚNIOR, 2017, p. 985).

Andrès (1998), Silva (2009), Reis (2010) e Lima (2014) destacam como essas descontinuidades possuem relação com a dinâmica política local, onde sucessivos governos utilizaram o patrimônio como vetor político fazendo com que as políticas do patrimônio tivessem distintos momentos. Ressalte-se, que a redução do número de residentes ocorre de forma relativamente equilibrada entre o sexo masculino e feminino, como se observa no gráfico $\mathrm{n}^{\mathrm{o}} 02$.

Gráfico nº 02 - Variação do número de residentes por Sexo.

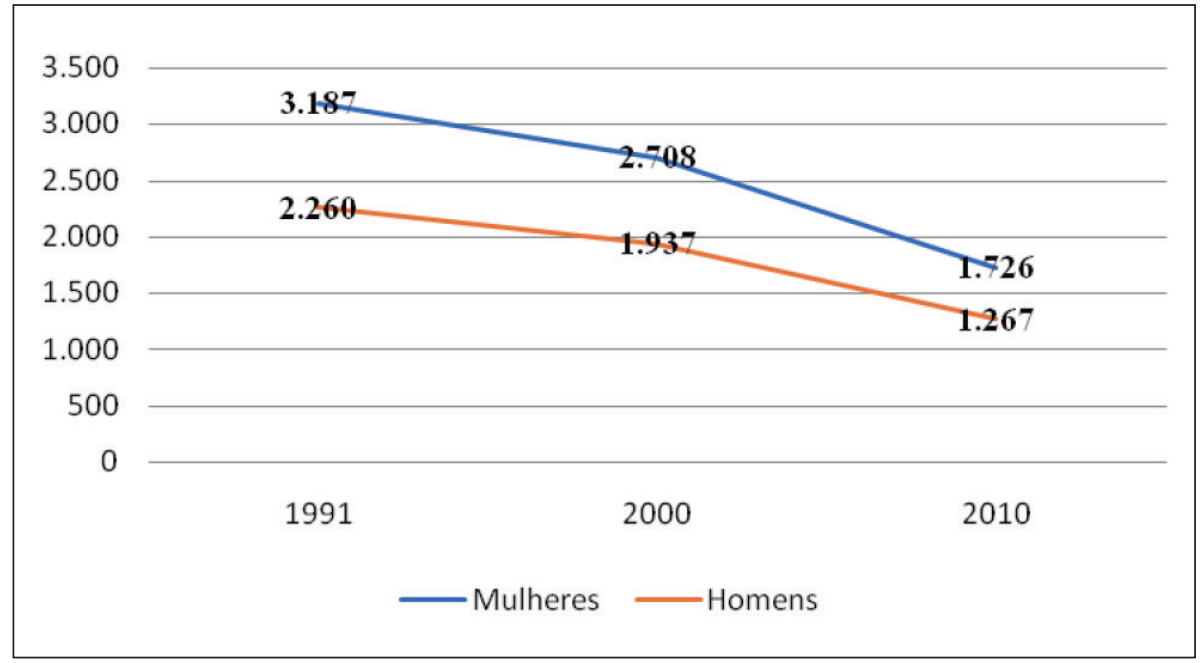

Fonte: Autoria Própria com base em dados do IBGE

A classificação por faixas etárias desses moradores é um elemento interessante para um melhor embasamento sobre o perfil populacional dos residentes, bem como perceber se além do decréscimo populacional está ocorrendo também um vertiginoso envelhecimento que pode contribuir para continuidade dessa redução.

Em relação às faixas etárias da população residente foram segmentados quatro grupos para compreender variações no perfil de idade. Na categoria de criança e adolescente, se considerou o indivíduo com até quatorze anos completos. Para ser caracterizado como jovem foi utilizado como referência 
etária de 15 até 29 anos, os adultos as pessoas de 30 a 59 anos e na categoria de idosos todas as pessoas com 60 anos ou mais de idade ${ }^{6}$.

Em 1991, a faixa etária com maior número de indivíduos era a de jovens respondendo por 35\% (trinta e cinco por cento). Em seguida, a faixa etária das crianças e adolescentes com $26 \%$ (vinte e seis por cento). Somadas essas duas faixas etárias tem-se uma população de 61\% (sessenta e um por cento) dos residentes com até 29 anos de idade, o que denota a predominância de uma população jovem.

Na parte de cima da pirâmide a população em idade adulta correspondia por $25 \%$ (vinte e cinco por cento) e os idosos somente por 14\% (quatorze por cento). Essa era a composição etária da população residente no centro histórico em 1991.

Em 2000 a pirâmide etária denota modificações na estrutura dos grupos de idade na população com um aumento da proporção de indivíduos do meio para o topo da pirâmide através do incremento de pessoas classificadas como adultas e idosas.

Os dados apontam para o contínuo processo de envelhecimento da população moradora do centro histórico, pois no censo de 1991 a faixa etária com o maior número de pessoas era a dos enquadrados como jovens, que em 2000 perde o posto para a dos adultos. Esse fenômeno encontra-se situado dentro do que vem ocorrendo no perfil populacional brasileiro, através da mudança demográfica que se torna mais nítida a partir da década de 1970 do século XX (MIRANDA, 2016, p. 508).

Com relação aos idosos, apesar do número em termos absolutos continuar na última posição, em termos proporcionais passa a ter maior peso na pirâmide etária, visto que apesar da diminuição do número residentes no centro histórico, o número absoluto de idosos no Censo 2000 se apresenta em quantitativo superior ao do recenseamento anterior.

Reportagem da edição de 08.09.2001 do jornal O Estado do Maranhão apresenta entrevistas com senhoras idosas residentes em casarões do centro histórico de São Luís. Exemplos emblemáticos da vida nas edificações tom-

6 Foi considerada para formulação da pirâmide etária a seguinte legislação: Lei $\mathrm{n}^{\circ} 8.069$ de 13 de julho de 1990 , Lei $n^{\circ} 10.741$ de $1^{\circ}$ de outubro de 2003 e a Lei $n^{\circ} 12.852$ de 05 de agosto de 2013. Ressalta-se que em razão da Lei 8.069 e da Lei 12.852 referirem-se de forma simultânea aos indivíduos de 15 a 18 anos - cada uma dentro de sua abrangência - optou-se por caracterizar essas pessoas como jovens. 
badas. A matéria inicia reproduzindo a relação da senhora Laura Rosa de Sousa Pires Neves Braúna com o seu casarão situado no Beco da Pacotilha.

Dona Laura na época com seus 87 anos residia "com um filho adotivo e uma auxiliar", bem como na companhia de seus nove gatos. Em razão da dificuldade de locomoção pela idade a anciã já não circulava por todos os ambientes devido o acesso ser dificultado pela existência de uma escada. Por esse motivo a idosa manifestava seu desejo de se mudar do centro histórico: "Dona Rosita diz que quer se desfazer do casarão onde mora. Para isso, vai tentar vendê-lo ao governo e, com o dinheiro, comprar uma casa menor e sem escadas" (O ESTADO DO MARANHÃO, 2001, Caderno especial São Luís 389 anos, p. 11).

Figura 03 - Dona Laura e seus felinos.

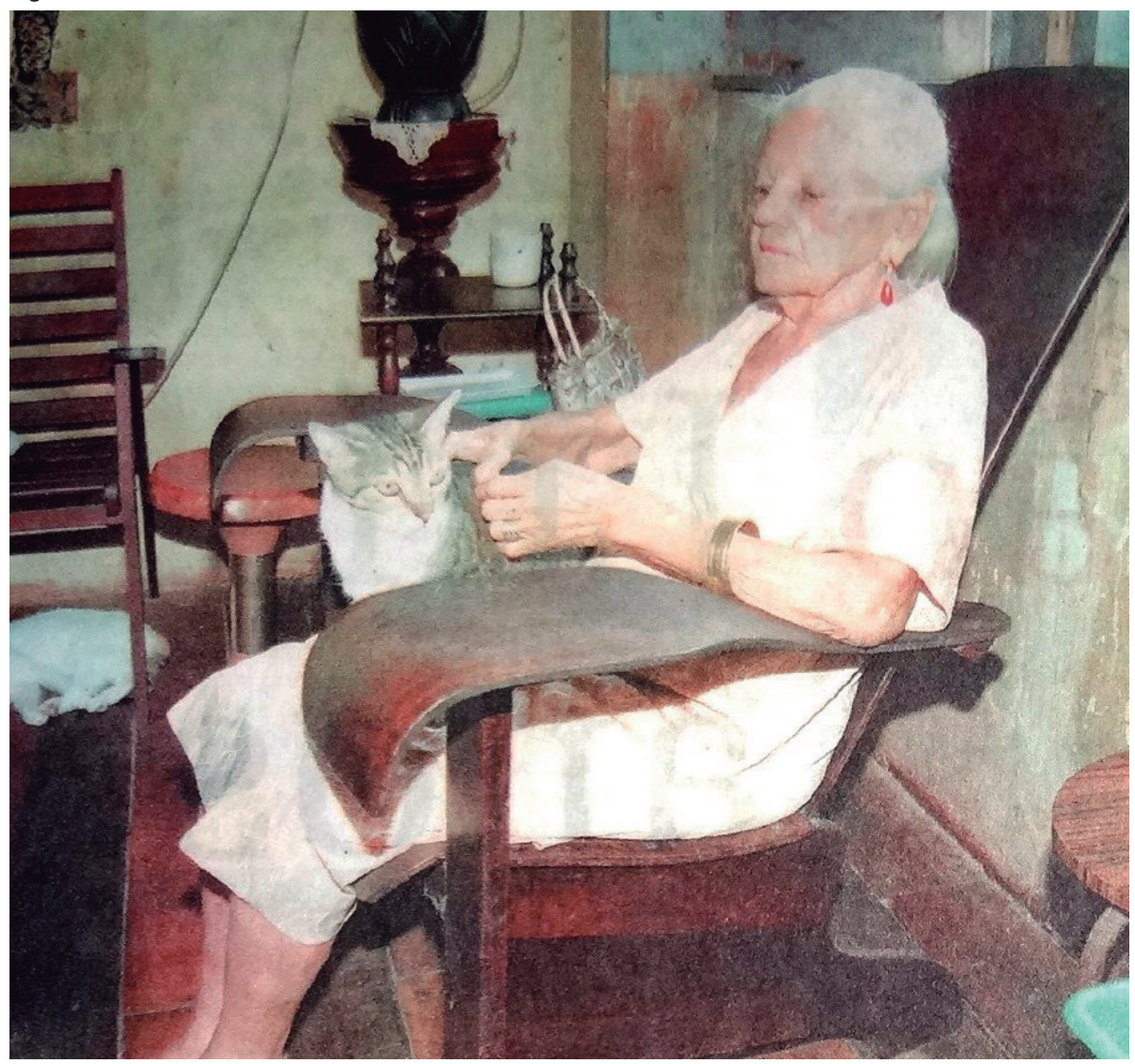

Fonte: O Estado do Maranhão, 2001, Caderno especial 389 anos, p. 11. 
A reportagem traz ainda histórias da vida de Dona Nenen de 88 anos, que é moradora de um antigo casarão próximo ao de Dona Rosita, com toda sua família: "Filhos, netos e bisnetos" como costuma frisar. Ao contrário de Dona Rosita, que não possui condições de subir escadas, Dona Nenen costuma subir até o mirante do casarão para admirar a paisagem da Baía de São Marcos "mesmo depois de estar morando no lugar há 60 anos" (O ESTADO DO MARANHÃO, 2001, Caderno especial São Luís 389 anos, p. 11). Outro exemplo marcante de relação entre moradores e seus imóveis históricos é o de Dona Vitória Perez Santos Castro, 85 anos.

A relação de Dona Vitória com casarão localizado na rua Humberto de Campos, 200, esquina com a Praça João Lisboa, existe há muitos anos, mas só se tornou pública no dia 28 de abril de 1999, quando ela foi retirada do sobrado praticamente à força pelos soldados do Corpo de Bombeiros. O sobrado ameaçava ruir e ela se negava a deixá-lo. Para sua segurança teve que ser retirada (O ESTADO DO MARANHÃO, 2001, Caderno especial São Luís 389 anos, p. 13).

Segundo a reportagem do periódico, Dona Vitória sempre teve sua vida relacionada com os casarões desde o seu nascimento. E almeja só sair do casarão da Rua Humberto de Campos após seu falecimento. Por isso, a idosa ainda guarda na lembrança detalhes e mágoa da sua abrupta retirada do imóvel em que residia. "Não me deram nem satisfação. Amarraram meu corpo nos braços e me levaram mesmo contra minha vontade. Não perdoo os bombeiros por isso" (O ESTADO DO MARANHÃO, 2001, Caderno especial São Luís 389 anos, p. 13). Essas histórias de vida demonstram um apego especial das pessoas que durante décadas mantiveram suas residências e suas vidas em imóveis do centro histórico.

O aumento do número de residentes idosos no centro histórico é registrado com a construção da pirâmide etária para examinar a distribuição nas faixas de idade existentes do Censo Demográfico 2010. Na referida jornada censitária a composição das faixas de idade dos residentes mantém a tendência capturada no censo anterior, na qual se apresenta diminuição da base e o alargamento do topo. Para fins de mensuração em 2000 a soma de adultos e idosos perfazia 50\%, em 2010, esse percentual cresceu para 57\%, superando pela primeira vez a soma de crianças, adolescentes e jovens.

Ao se confrontar os dados da população total de residentes da área com os obtidos na construção da pirâmide etária, constata-se que além de uma 
redução constante, e inclusive mais acelerada entre os dois últimos censos demográficos, ocorre também um contínuo envelhecimento da população residente no centro histórico. Referido cenário aponta para uma situação de maior decréscimo populacional nas próximas décadas, se não ocorrerem políticas públicas na tentativa de reverter esse quadro.

Gráfico nº 03 - Variação dos grupos etários.

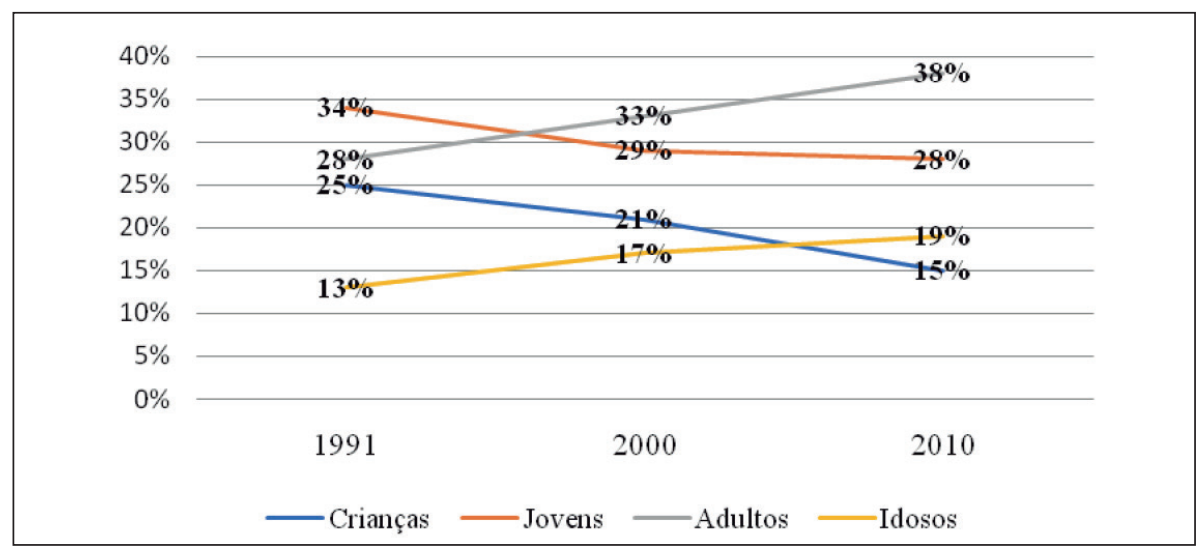

Fonte: Autoria Própria a partir de dados do IBGE

O gráfico de $\mathrm{n}^{\circ} 03$ permite uma melhor visualização do acentuado processo de envelhecimento da população residente no centro histórico, com a linha curva de crescimento ascendente para os grupos de idosos e adultos. Em sentido contrário, se apresenta decrescente a curva dos grupos etários de crianças e jovens, especialmente no caso das crianças e adolescentes.

Os dados do censo de 2010 possibilitaram a construção de gráfico da representação dos residentes por cor/raça ${ }^{7}$. Esse gráfico foi elaborado para ilustrar informações sobre como se autodeclaram em relação ao quesito cor/ raça os residentes do centro histórico e com isso refinar melhor a caracterização dos residentes.

A composição racial obtida pelo Censo Demográfico de 2010 é oriunda da auto declaraçãode pertencimento atribuída pela própria pessoa respondente da pesquisa. Observa-se que os indivíduos autodeclarados como pardos são

7 Em 2010, último censo realizado, repetiram-se as mesmas categorias de classificação da pergunta, que voltou ao questionário básico aplicado à totalidade da população, sendo que, pela primeira vez, as pessoas identificadas como indígenas foram indagadas a respeito de sua etnia e língua falada (IBGE, 2011). 
maioria, sendo acompanhados por números bem próximos das pessoas que se declararam brancas. Esses dois grupos somados representam quase noventa por cento do total de residentes.

Apesar de em termos gerais os que se autodeclaram como de cor amarela representarem menos de um porcento do total de residentes é interessante acompanhar nas próximas jornadas censitárias se ocorre o aumento desse grupo, visto ser notório dentro da área do centro histórico de São Luís a fixação de pessoas de origem oriental nos últimos anos. Desse modo, será necessário esperar o próximo recenseamento para perceber se a chegada desses indivíduos terá capacidade de alterar de forma mais consistente a divisão apresentada pelo último censo demográfico.

Gráfico nº 04 - Residentes por cor/raça.

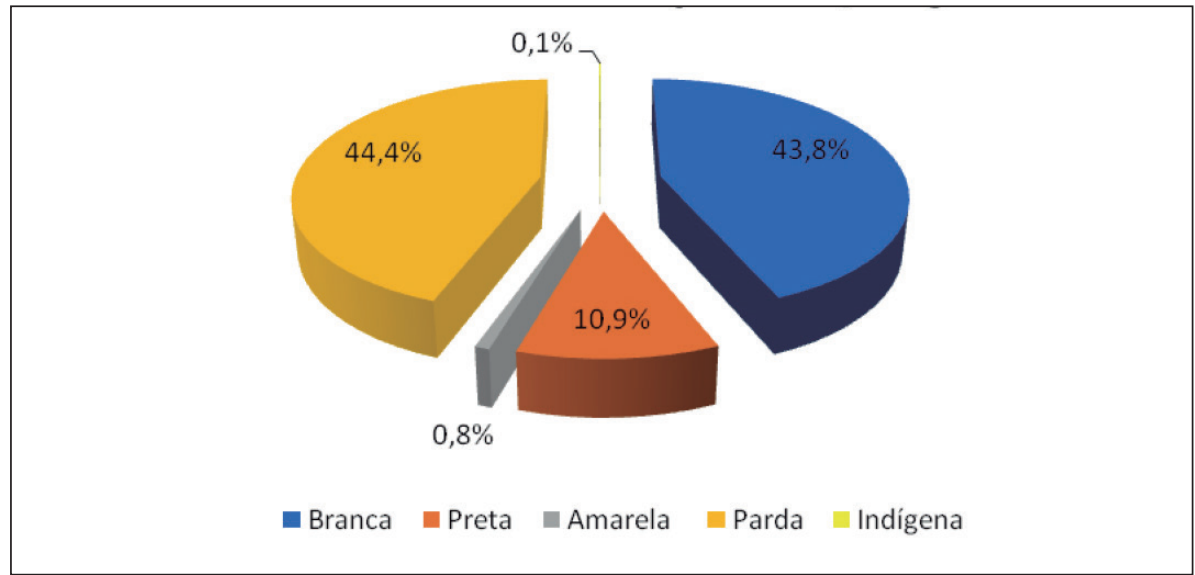

Fonte: Autoria Própria a partir de dados do IBGE

Com as informações construídas nos gráficos sobre as características gerais do moradores do centro histórico se depreende ser a área habitada em grande parte por uma população feminina autodeclarada parda/preta.

\section{A configuração dos domicílios na área histórica}

A tabulação de dados atinentes às características dos domicílios da área tombada possibilitou um conjunto de informações mais precisas sobre aspectos das residências no centro histórico, tais como: variação do número e do tipo de domicílios existentes na área. 
O censo demográfico de 1991 apontou existirem de 1.161 (mil cento e sessenta e um) domicílios particulares permanentes ${ }^{8}$, com o do tipo casa contando com 1.088 (mil e oitenta e oito) unidades. Ao se contar também os domicílios coletivos ${ }^{9}$, que somavam 38 (trinta e oito), obtêm-se ao total de 1.199 (mil cento e noventa e nove) domicílios existentes.

O número de domicílios do tipo apartamento somava apenas 52 (cinquenta e duas) unidades e os classificados como cômodos, espécie classificada"por um ou mais aposentos localizados em uma casa de cômodos, cortiço, cabeça de porco, etc.” (IBGE, 2003, p. 10), perfazia um total de 21 (vinte uma) unidades domiciliares. Portanto, é possível afirmar que na área de preservação histórica, existe uma clara preponderância do tipo domiciliar classificado como casa. Tal fato não é de se estranhar em razão do transcurso de formação desse espaço urbano, bem como das limitações de caráter normativo oriundas dos tombamentos realizados.

Em relação às características dos domicílios, o censo demográfico de 2000 traz dados interessantes em relação aos tipos de domicílios existentes no centro histórico. No ano de 2000, os domicílios do tipo casa, apesar do decréscimo percentual verificado, ainda se apresentam como predominantes com $82,5 \%$ do total, contudo se esse tipo de unidade domiciliar ainda prepondera de forma majoritária, é necessário destacar que ocorre um significativo crescimento do tipo apartamento que salta de $4,5 \%$ para $7,1 \%$, ou seja, um aumento de 58\% entre 1991 e 2000.

O crescimento do número de apartamentos deve-se à implantação de projetos de moradia com a reforma e adaptação de imóveis em habitações no formato de apartamentos. Tal fato ocorreu dentro do planejamento de ações do poder público para dar nova destinação para imóveis de grande porte do conjunto arquitetônico tombado.

Em que pese a atuação governamental através de projetos de habitação o destaque negativo fica por conta do grande crescimento das moradias do tipo cômodos, denotando a formação de cortiços que saltam de 1,8\% para

8 Domicílio particular permanente é a unidade construída para servir exclusivamente à habitação e, na data de referência, tinha a finalidade de servir de moradia a uma ou mais pessoas (IBGE, 2003, p. 9).

9 Domicílio coletivo, quando a relação entre as pessoas que nele habitavam era restrita a normas de subordinação administrativa, como em hotéis, pensões, presídios, cadeias, penitenciárias, quartéis, postos militares, asilos, orfanatos, conventos, hospitais e clínicas (com internação), alojamento de trabalhadores, motéis, camping, etc. (IBGE, 2003, p. 10). 
10,4\% dos domicílios. Esse tipo de unidade domiciliar teve o maior incremento dentre os dois períodos em comparação.

Esse aumento bastante significativo do tipo definido como cômodo inclusive fornece explicação para compreender a razão de apesar do número de residentes ter se reduzido entre os censos de 1991 e 2000, haver ocorrido um leve aumento do número total de domicílios particulares permanentes na área tombada entre 1991 e 2000.

\section{Figura 05- Cortiço na zona histórica.}

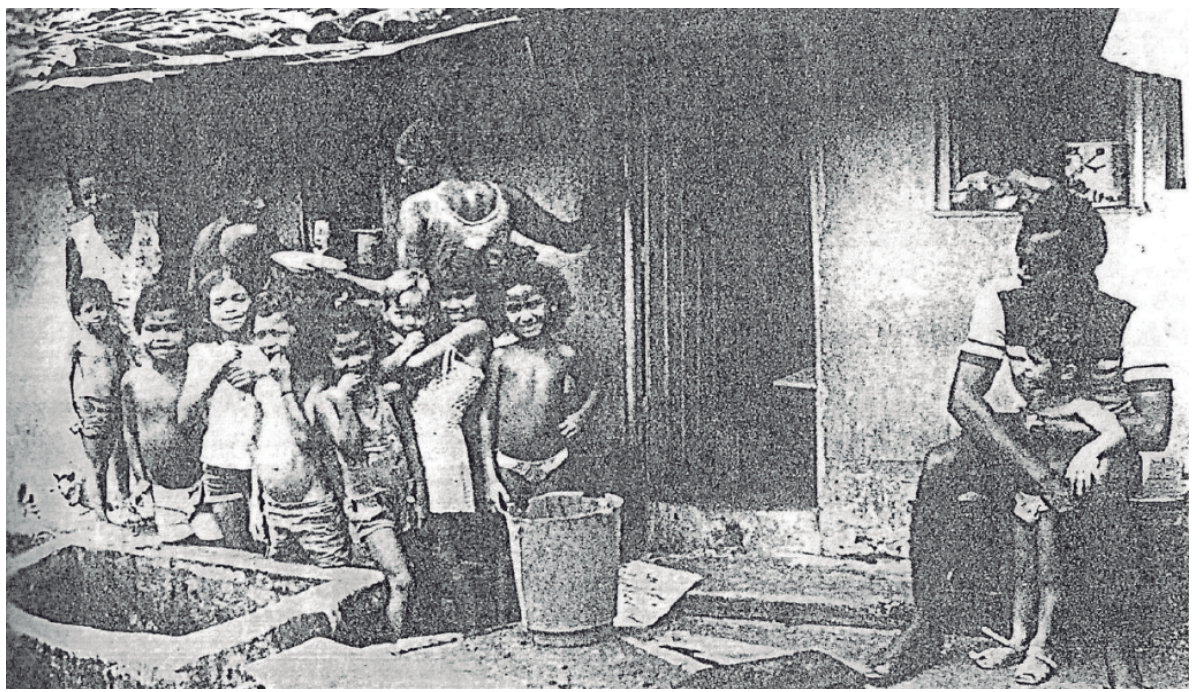

Fonte: MARANHÃO, 1986, p. 48

Se em 1991, foi apurada a existência de 1.161 domicílios, em 2000, esse número cresce para 1.174. Essa pequena variação positiva de treze unidades domiciliares encontra explicação na transformação de alguns imóveis em unidades do tipo apartamento, mas também no processo de encortiçamento verificado no período entre os dois censos mencionados.

O fato é que o uso do solo e formas de ocupação pelas classes populares, no centro antigo de São Luís foram considerados como um problema, pois estes usos e formas tornaram-se indesejáveis e inadequados aos olhos das instituições dominantes. Sabe-se que os resultados do projeto de intervenção foram restritos e, portanto, insuficientes para renovar as paisagens desejadas e eliminar na totalidade as que já historicamente estão posicionadas em função do contexto da reocupação do centro no passado (SILVA, 2010, p. 176). 
O problema da forma de ocupação dos imóveis é um dos desafios para os órgãos de gestão do centro histórico. Cabe destacar que no censo de 2010, apesar da manutenção da predominância de unidades domicilares do tipo casa com 86\% do total,os dados da jornada censitária apresentam uma significativa alteração, pois as unidades do tipo apartamento superam o número de domicílios do tipo cômodos. O percentual de cômodos ainda existentes demonstra que o quesito habitação necessita de atenção dos órgãos de gestão patrimonial, através da implantação de uma política habitacional, que além do caráter social, poderia ter o fito de estancar o esvaziamento do centro histórico

O gráfico $\mathrm{n}^{0} 05$ permite visualizar uma série histórica da variação do número de domicílios, na qual emergem números interessantes para reflexão da situação do centro histórico de São Luís. Ao contrário do ocorrido com o número de residentes, que apresenta queda de forma ininterrupta no período pesquisado, o quantitativo total de domicílios perpassa entre os anos de 1991 e 2000, por uma pequena elevação, tanto dos domicílios particulares permanentes ou mesmo da soma destes acrescentados aos domicílios coletivos existentes.

Gráfico nº 05 - Variação do número de domicílios.

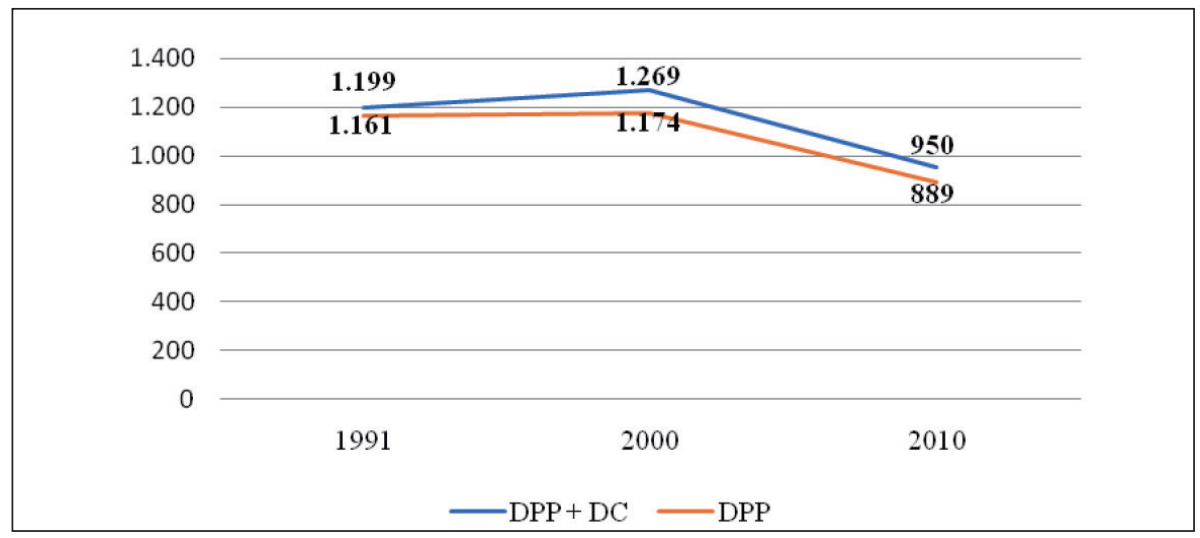

Fonte: Autoria Própria com base em dados do IBGE

Essa variação ocorrida inicialmente no período de análise pode ser atribuída em parte ao programa de habitação desenvolvido na área onde imóveis foram reformados e passando a ser utilizado como apartamentos. Em 1993 um sobrado em ruínas, habitado como cortiço, foi reconstruído e adap- 
tado em formato de apartamentos para famílias de trabalhadores e antigos moradores (ANDRÈS, 2012, p. 11).

Apesar dessa iniciativa que rememorava ao planejamento dos primórdios do PPRCH, o aumento do número absoluto de domicílios ocorreu também em razão da transformação de alguns imóveis em cortiços.

A afirmação exposta se escora na visualização do gráfico $\mathrm{n}^{\circ} 06$, através do qual pode-se conceber uma série histórica da representação por tipo de domicílio, é possível visualizar de forma mais significativa no tempo a dinâmica domiciliar.

Gráfico nº6 - Variação do tipo de domicílio.

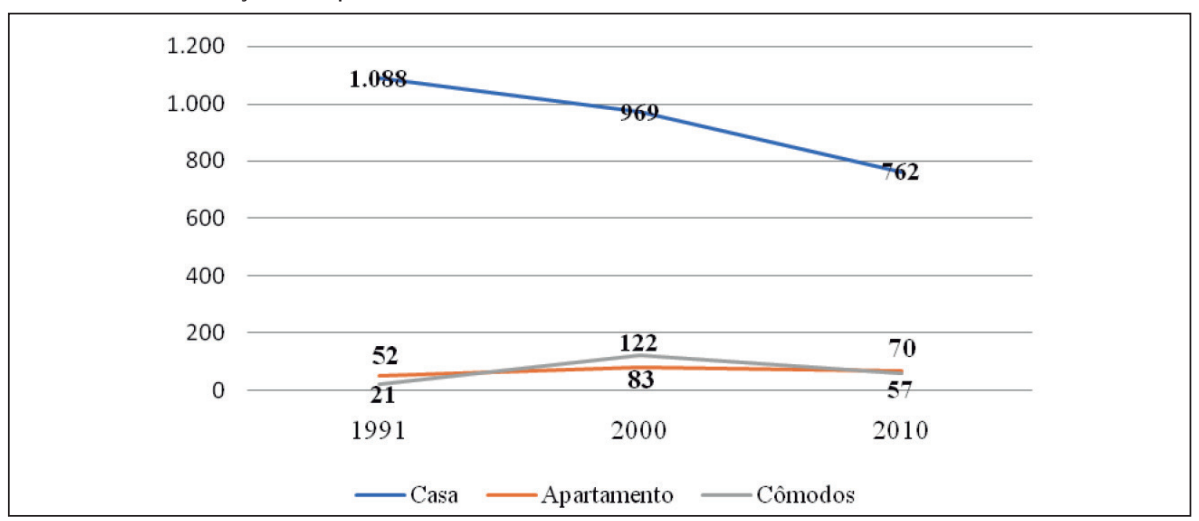

Fonte: Autoria Própria com base em dados do IBGE

Apesar do aumento do número total de domicílios entre os anos de 1991 e 2000, recordando-se que no mesmo período ocorreu a redução do número de moradores, esse acréscimo não foi de maneira uniforme entre os tipos de domicílio. Ao contrário, ocorre uma permanente redução do domicílio do tipo casa, mas os do tipo apartamento e cômodos, entre os anos de 1991 e 2000, experimentam um acréscimo para no decênio seguinte também sofrerem redução.

Os domicílios do tipo apartamento e cômodos aumentam em número de unidades: 59,62\% e 480,25\% respectivamente entre os anos de 1991 e 2000. Com relação aos números apresentados chama atenção o grande aumento de três dígitos dos domicílios do tipo cômodos. Demonstrando que muitos dos imóveis tombados se encontravam em processo de encortiçamento, o que denota um crescimento da pobreza na área tombada.

Entretanto, no período compreendido entre os anos de 2000 e 2010 acompanhando a acentuada diminuição do número de residentes, ocorre dimi- 
nuição de todos os três tipos de domicílio, em especial os do tipo cômodos, que recuam em torno de 53,27\%.

Os números registrados nos gráficos indicam, com suas permanências e variações no decorrer das décadas analisadas, marcantes mudanças nas características dos moradores e dos domicílios no centro histórico. De forma inequívoca está configurando o fenômeno do esvaziamento populacional no centro histórico, a despeito das políticas públicas de investimento em projetos de revitalização na área. Esse fato decorre não somente da ausência de uma política pública consistente para a área tombada, mas também da própria dinâmica de organização espacial da cidade de São Luís.

\section{Conclusão}

O uso dos agregados por setores censitários para elaboração de uma classificação da evolução demográfica do centro histórico de São Luís, através da formulação de séries estatísticas com informações múltiplas das pessoas residentes e dos domicílios é uma valiosa fonte para se analisar permanências e/ou variações demográfica socorridas no decorrer de mais de três décadas de ações patrimoniais.

Com base nas informações estruturadas, é possível afirmar que a política patrimonial de reformas pontuais em imóveis no centro histórico de São Luís foi capaz de proteger apenas uma porção ínfima dos exemplares monumentais de edificações, assim como salvaguardando algumas das mais excepcionais construções, que sem a contribuição dos programas de preservação provavelmente teriam sido destruídas ao longo dos anos. Contudo, não se implantou um plano de intervenções abrangente e com capacidade de integrar o centro histórico, através da reutilização de seu conjunto urbano, no sentido de torná-lo novamente um local atrativo de fixação de residências. Esse cenário atrelado ao rápido processo de expansão da cidade no último quartel do século XX para sua parte norte, orla marítima, e sul, distrito industrial, são os elementos do vertiginoso e contínuo declínio populacional de residentes na área.

Desse modo, apresenta-se como fundamental a formulação de políticas públicas de longo prazo e ações no intuito de reverter essa tendência, pois mantido o atual cenário, o acervo arquitetônico de tipologia lusa tombado será reduzido a um local essencialmente de visitação turística, em razão do 
contínuo esvaziamento das edificações, inclusive contribuindo para sua deterioração dos inúmeros imóveis fechados/abandonados.

Para evitar esse quadro é essencial que as políticas públicas de preservação do patrimônio histórico considerem de forma prioritária, dentro do processo de revitalização do acervo arquitetônico, temas como: instalação de serviços e equipamentos públicos, mobilidade urbana e habitação. Essas diretrizes precisam ser consideradas pelos agentes governamentais, mas com a participação dos moradores, usuários e agentes econômicos da área na elaboração de políticas e ações no intuito de uma plena reabilitaçãode maneira democrática e sustentável do centro histórico de São Luís.

\section{Referências}

ANDRÈS, Luiz Phelipe de Carvalho Castro (Coord.) (1998). Centro Histórico de São Luís-MA. Patrimônio mundial. São Paulo: Audichomo.

, Luiz Phelipe de Carvalho Castro (2012), Reabilitação do Centro Histórico-Patrimônio da Humanidade.

GIOVANNONI, Gustavo (2009), Gustavo Giovanonni: Textos Escolhidos. Cotia, São Paulo: Fapesp.

IBGE (2003), Censo Demográfico 2000: Agregado por Setores Censitários dos Resultados do Universo. 2ª ed. Rio de Janeiro: IBGE.

(2011), Características étnico-raciais da população: um estudo das categorias de classificação de cor ou raça 2008. Rio de Janeiro: IBGE.

(2011), Base de informações do Censo Demográfico 2010: Resultados do Universo por setor censitário, Rio de Janeiro: IBGE.

LIMA. Elaine Ferreira (2014), Da nação ao mercado: patrimônios mundiais e intervenções urbanas em perspectiva comparada. $271 \mathrm{f}$. Tese (Doutorado). Programa de Pós-Graduação do Departamento de Sociologia da Faculdade de Filosofia, Letras e Ciências Humanas. São Paulo: USP.

LINO. Fernanda Noia da Costa (2010). A preservação do patrimônio cultural urbano: fundamentos, agentes e práticas urbanísticas. $187 \mathrm{f}$. Tese (Doutorado). Programa de Pós-Graduação do Departamento de Sociologia da Faculdade de Filosofia, Letras e Ciências Humanas. São Paulo: USP.

LOPES, José Antonio Viana (org) (2008), São Luís Ilha do Maranhão e Alcântara: guia de arquitetura e paisagem. Ed. Bilingüe. Sevilla: Consejaría de Obras Públicas y Transportes, Dirección General de Arquitectura y Vivienda.

MARANHÃO, Secretaria de Coordenação e Planejamento (1986a). Projeto 
de Urbanização da Praia Grande - 1ª etapa: Plano de Circulação no Centro Histórico (PCCH). São Luís, 1981. Secretaria de Coordenação e Planejamento. Programa de Preservação e Revitalização do Centro Histórico de São Luís (Projeto Praia Grande) - versão preliminar período 1987/1991. São Luís/MA.

MIRANDA, Gabriella Morais Duarte; MENDES, Antonio da Cruz Gouveia; SILVA, Ana Lucia Andrada da (2016), "O envelhecimento populacional brasileiro: desafios e consequências sociais atuais e futuras". Rev. bras. geriatr. gerontol., Rio de Janeiro, v. 19, n. 3, p. 507519, Jun. Disponível em: <http://www.scielo.br/scielo.php?script=sci arttext\&pid $=$ S1809-98232016000300507 \&lng =en\&nrm=iso $>$. Acesso em 03 Jan. 2019.

MERLLIÉ, Dominique et al (1996). Iniciação a prática sociológica. Petrópolis: Vozes.

O ESTADO DO MARANHÃO, São Luís, 08 set. 2001 (jornal).

PEREIRA, Marcio Rodrigo da Silva; ALCANTARA JR, José O. (2017), “A mobilidade e a expansão territorial na cidade de São Luís, MA: um novo paradigma social na ocupação do espaço urbano”. Cad. Metrop., São Paulo, v. 19, n. 40, p. 977-998, Dez. Disponível: <http://www.scielo.br/scielo. php?script $=$ sci_arttext\&pid $=$ S2236-99962017000300977\&lng $=$ en\&nrm $=\mathrm{i}$ so>. Acesso em 02 Jan. 2020. http://dx.doi.org/10.1590/2236-9996.2017-4012.

REIS, Eliana Tavares dos (2010), "Em nome da "cultura”: porta-vozes, mediação e referenciais de políticas públicas no Maranhão”. Soc. estado [online], vol. 25, n.3, pp. 499-523. Disponível em < http://www.scielo.br/ scielo.php?script $=$ sci_arttext\&pid $=$ S0102-69922010000300005\&lng $=e n \& n$ $\mathrm{rm}=$ iso $>$. Acesso em $\overline{1}$ de abril de 2020.

SILVA, Georgia Patrícia da (2010). De volta à Praia Grande: o "velho" centro com o "novo" discurso. 200 f. Tese (Doutorado em Políticas Públicas) Universidade Federal do Maranhão, São Luís.

SILVA, João Ricardo Costa (2009), A Construção do Patrimônio: a trajetória de preservação do Centro Histórico de São Luís. 193 f. Dissertação (Mestrado em Ciências Sociais) - Universidade Federal do Maranhão, São Luís.

UNESCO (2009), “Carta de Nairobi 1976 - Recomendação sobre a salvaguarda dos conjuntos históricos e da sua função na vida contemporânea”. Cadernos de Sociomuseologia, América do Norte, 15. Disponível em: < http://revistas.ulusofona.pt/index.php/ cadernosociomuseologia/article/view/339/248> . Acesso em: 20 Dez. 2018.

\section{(c) $) \mathrm{EY}$}

Licenciado sob uma Licença Creative Commons Attribution 3.0 